\title{
CICLOS DE PROTESTO E DEMOCRACIA Uma comparação entre Portugal e Espanha, 2000-2019
}

\author{
Tiago Fernandes \\ Iscte - Instituto Universitário de Lisboa, Centro de Investigação e Estudos de Sociologia \\ (CIES-Iscte), Lisboa, Portugal \\ Cláudia Araújo \\ Faculdade de Filosofia, Universidade de Barcelona, Espanha \\ Isabel Gorjão Santos \\ Faculdade de Ciências Sociais e Humanas, Universidade Nova de Lisboa, Lisboa, Portugal \\ Eduardo Romanos \\ Facultad de Ciencias Políticas y Sociología, Universidade Complutense, Madrid, Espanha
}

Resumo Neste artigo, são descritos e analisados os ciclos de protesto em Portugal e Espanha no início do século XXI. Considerando que a possibilidade de exercer o direito à dissensão na esfera pública constitui não apenas um dos elementos caracterizadores da democracia, mas igualmente um fator do seu fortalecimento, esta análise compara os ciclos de protesto nos dois países da Península Ibérica, atentando à sua magnitude e complexidade organizacional, e aos seus aspetos culturais, em particular os repertórios de ação coletiva. Este estudo permite identificar diferentes tendências do protesto nos dois países, não obstante a Grande Recessão constituir, em ambos os casos, um marco inquestionável em termos da dimensão do protesto. Permite igualmente aferir da constante importância de atores de protesto tradicionais em Portugal, como os sindicatos, associada à existência de uma cultura de protesto mais democrática. Em contrapartida, em Espanha, a arena do protesto é mais variada e inovadora, mas também mais polarizada e conflitual.

Palavras-chave: protesto, democracia, Grande Recessão, Portugal, Espanha

Protest cycles and democracy: a comparison between Portugal and Spain, 2000-2019

Abstract This article analyses and compares the protest cycles of Portugal and Spain in the first two decades of the 21st century. Considering that the possibility of exercising the right to dissent in the public sphere constitutes one of the key characteristic elements of democracy, but is also a factor of its consolidation, this analysis contributes to the understanding of protest as a legitimate form of political participation in the Iberian Peninsula. Specifically, it looks at its magnitude, organizational complexity and cultural aspects, in particular the repertoires of collective action. While it demonstrates that the Great Recession was a landmark in terms of the dimension of protest events in both countries, this study also identifies different patterns of popular dissent. In Portugal, traditional protest actors, like unions, prevail, and are part of a more democratic protest culture, whereas in Spain, there is a more varied and innovative arena of protest, albeit significantly more fractured and polarised.

Keywords: protest, democracy, Great Recession, Portugal, Spain

Cycles de contestation et démocratie: une comparaison entre le Portugal et l'Espagne, 2000-2019

Resumé Cet article analyse les cycles de contestation au Portugal et en Espagne au début du XXIe siècle. Considérant que la possibilité d'exercer le droit à la dissension dans la sphère publique constitue l'un des éléments caractéristiques clés de la démocratie, mais aussi un instant de sa consolidation, cette analyse contribue à la compréhension de la contestation comme forme légitime de participation politique en Péninsule Ibérique, en donnant compte de son ampleur, de sa complexité organisationnelle et de ses aspects culturels, en particulier les répertoires d'action collective. Tout en démontrant l'importance de la Grande Récession en tant que jalon en termes de dimension des actes de démocratie désobéissante dans les deux pays, cette étude identifie également 
différentes tendances de contestation populaire. Alors qu'au Portugal, ce sont les acteurs, les actions et les revendications traditionnels, comme les syndicats, aussi associés à l'existence d'une culture de protestation plus démocratique, qui occupent une place centrale, en Espagne, on trouve une arène plus variée et innovante de la contestation, bien que nettement plus fracturée et polarisée.

Mots-clés: protestation, démocratie, Grande Recession, Portugal, Espagne

Ciclos de protesta y democracia: una comparación entre Portugal y España, 2000-2019

Resumen Este artículo analiza y compara los ciclos de protesta de Portugal y España en las dos primeras décadas del siglo XXI. Considerando que la posibilidad de ejercer el derecho a la disensión en la esfera pública constituye uno de los elementos clave característicos de la democracia, y es también un factor de su consolidación, este análisis contribuye a la comprensión de la protesta como una forma legítima de participación política en la democracia en la Península Ibérica. En concreto, analiza su magnitud, complejidad organizativa y aspectos culturales, en particular los repertorios de acción colectiva. Si bien demuestra que la Gran Recesión fue un hito en términos de la dimensión de los eventos de protesta en ambos países, este estudio también identifica diferentes patrones de disensión popular. En Portugal, los actores tradicionales de la protesta, como los sindicatos, prevalecen y son parte de una cultura de protesta más democrática, mientras que en España hay un escenario de protesta más variado e innovador, aunque significativamente más fracturado y polarizado.

Palabras-clave: protesta, democracia, Gran Recesión, Portugal, España

\section{Introdução}

Este artigo constitui uma análise comparada da natureza e do impacto do protesto em Portugal e em Espanha no período 2000-2019. ${ }^{1}$ A participação de cidadãos comuns, por definição sem acesso às instituições de decisão política, em movimentos sociais e ações de protesto, pode ser considerada como uma prática democrática, no sentido em que contribui para aumentar o controlo popular sobre as decisões do estado, modificar a agenda governativa, transformar culturas, politizar grupos tradicionalmente quiescentes e passivos e solidificar laços cívicos entre os cidadãos. Se é verdade que nem todos os ciclos de protesto aprofundam a democracia, sobretudo quando são caracterizados pela generalização da violência, é também difícil conceber um regime democrático sem protesto. Desta forma, analisar a cultura do protesto e os seus níveis de institucionalização é também uma forma de avaliar a consolidação e a qualidade da democracia (Amenta, 2006; Ekiert e Kubik, 1999; Dolenec et al., 2019; Goss, 2006; Tarrow, 1990, 1995 e 1997).

1 Este artigo e os dados em que se baseia são parte do projeto de investigação “Disdem - Disobedient Democracy", financiado pela Fundação Nacional para a Ciência Suíça e dirigido por Danijela Dolenec, da Faculdade de Ciência Política da Universidade de Zagreb. Agradecemos os comentários e sugestões a diversas versões de Danijela Dolenec, Grzegorz Ekiert, Jan Kubik, Ana Balkovic, Daniela Sirinic, Karlo Krarj, Pedro Tavares de Almeida, Luís de Sousa, Ricardo Paes Mamede, Rui Branco, Guya Accornero, Michael Bernhard, Robert Fishman, Julia Lopez e Igor Sádaba. 
Contudo, a intensidade e a forma de os cidadãos se envolverem em práticas de protesto são bastante variadas. Na verdade, nas democracias modernas, a esfera de ação coletiva fora das habituais instituições políticas é tão diversa quanto as instituições políticas "convencionais", como os sistemas partidários (bipartidários ou multipartidários), os mecanismos de representação de interesses (pluralista ou corporativista) ou os sistemas eleitorais (proporcionais ou maioritários) (Dolenec, 2017; Ekiert e Kubik, 1999). Este artigo compara os padrões de protesto dos dois países ibéricos a partir de duas grandes dimensões conceptuais. A primeira refere-se à magnitude e complexidade institucional do protesto (nos cinco pontos seguintes). Aqui é analisada a quantidade de eventos de protesto, a sua duração e volume de participantes, mas também abrangência territorial e social (classes e grupos sociais), tipo de organizadores e dinâmicas de coligação e alianças. Estes aspetos permitem avaliar a medida em que o protesto se tornou, ou não, uma forma de fazer política normal e aceite, generalizada pelo território e pela população, assim como a complexidade e desenvolvimento organizacional dos movimentos que o sustentam.

Em segundo lugar, estudamos os aspetos culturais do protesto (últimos dois pontos do artigo). A cultura do protesto inclui não só o conjunto de valores e crenças que condicionam a escolha de estratégias, modalidades de ação e tipo de reivindicações, mas aspetos mais profundos, como memórias de dinâmicas políticas passadas, expressas através de objetos e símbolos (canções, palavras de ordem, slogans e expressões típicas, etc.) (Banaszak, 1996: 34-36; della Porta et al., 2018; Fishman, 2011 e 2018). De particular importância são os denominados repertórios de ação coletiva, que constituem convenções culturais implícitas sobre os comportamentos de protesto admissíveis e imagináveis. As sociedades variam bastante nesta dimensão, que também pode ser vista como um indicador de qualidade da democracia, em particular quando o protesto é predominantemente pacífico, mesmo no âmbito de ações disruptivas, como ocupações, e quando o seu enquadramento cultural é inclusivo e universalista, não ficando restringido apenas às reivindicações específicas de determinados grupos sociais (Fishman, 2004; Tarrow, 1995: 90-99; Tarrow, 1997: 50-52; Tilly, 1986: 4-12).

Portugal e Espanha constituem dois casos paradoxais. São as duas democracias fundadoras da terceira vaga de democratização, localizando-se igualmente na semiperiferia da economia europeia e onde, durante o período em análise, considerado como o auge da era neoliberal (Hall e Lamont, 2013), o episódio da grande recessão (2010-2014) foi particularmente severo, o que gerou enormes vagas de protesto popular (della Porta et al., 2017; Portos, 2016; Carvalho, 2018). Ao mesmo tempo, apresentam padrões de protesto e ação coletiva radicalmente diferentes, $\mathrm{o}$ que coloca um puzzle empírico bastante interessante.

Em termos de metodologia, este artigo desenvolve uma análise de eventos de protesto (protest event analysis, $v d$. Hutter, 2014) e baseia-se na base de dados reunida pelo projeto "Disobedient Democracy", que reúne informação quantitativa sobre os ciclos de protesto em Espanha durante o período de 2000 a 2017 e em Portugal no período 2000-2019 (https://disdem.org/; vd. também Dolenec, 2017; Dolenec et al., 2019; Romanos e Sádaba, no prelo), recolhida em dois dos mais importantes jornais 
nacionais de cada país (Público e Diário de Notícias no caso de Portugal, El País e El Mundo no caso de Espanha). Os dados foram retirados a partir de uma análise de todas as edições dos dois jornais diários.

\section{A dimensão dos protestos}

Em Portugal, foi registado um total de 3363 eventos de protesto durante os 20 anos considerados, por contraste com 4101 em Espanha. ${ }^{2}$ A figura 1 mostra a distribuição dos eventos de protesto por ano, com a maior parte do período a registar um número de protestos mais elevado em Espanha do que em Portugal, exceto entre 2003 e 2005 e em 2008.

Os anos de maior ocorrência de protestos em Portugal foram 2001, 2008 e 2012. Em 2001, isso deveu-se à elevada mobilização de alunos do ensino secundário, estudantes universitários e trabalhadores, por oposição às reformas do sistema educativo (aumento das propinas nas universidades públicas) e às reformas económicas e sociais (privatização de serviços públicos e alterações da idade da reforma e na progressão de carreiras). Houve também elevados protestos a favor do aumento dos salários e de contestação ao apoio do governo português à intervenção norte-americana no Iraque.

Em 2008, mesmo nas vésperas da Grande Recessão, os protestos eram dirigidos contra as medidas do governo para alcançar a consolidação das finanças públicas, em linha com as políticas da União Europeia. Finalmente, 2012 corresponde ao pico da mobilização antiausteridade, em que indivíduos e organizações diversas se juntaram em coligações alargadas, sendo de destacar a plataforma "Que Se Lixe a Troika" (QSLT), que agregou as duas confederações sindicais e demais sindicatos, organizações de estudantes, movimentos de cidadãos vários, organizações e autoridades locais e representantes de todos os partidos de esquerda (Partido Socialista, Partido Comunista e Bloco de Esquerda) (Accornero e Ramos Pinto, 2015; della Porta et al., 2017; Fernandes, 2017 e 2018).

Nos anos seguintes, assistiu-se a um declínio sem paralelo do protesto, uma desmobilização abrupta dos movimentos sociais e atores de protesto tradicionais que estiveram envolvidos no intenso ciclo de protesto contra a austeridade, mas também refletindo a eventual expectativa positiva da sociedade civil em relação à solução governativa saída das eleições de 2015 - um governo de minoria socialista, cuja sobrevivência assentou em alianças com os mesmos partidos de esquerda - o Partido Comunista Português (PCP) e o Bloco de Esquerda (BE) - que tinham sido muito ativos durante o ciclo de protesto (Fernandes, 2018).

Espanha apresenta diferenças significativas em relação ao caso português. O primeiro período, que é de decréscimo da mobilização (2000-2005), poderá estar relacionado com a desmobilização do movimento social pela Justiça Global,

2188 eventos de protesto em Espanha não tinham, à data da elaboração deste artigo, data definida, não sendo considerados para a análise temporal do protesto. 


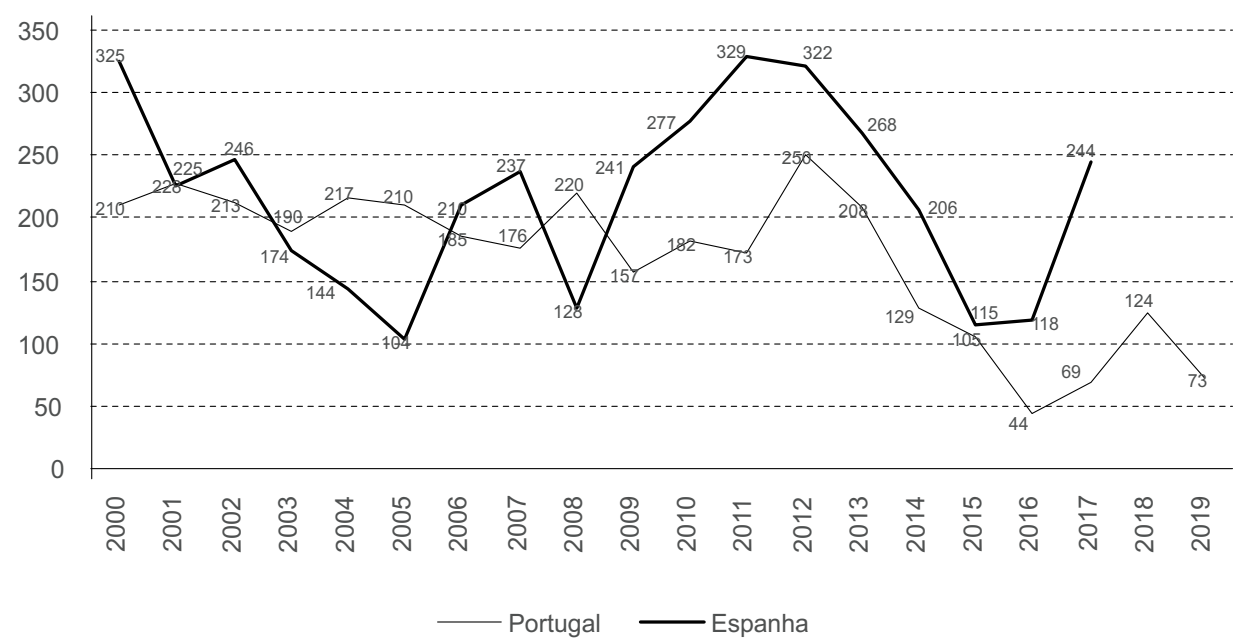

Figura 1 Número de eventos de protesto em Portugal e Espanha

Fonte: Disdem; elaboração própria.

associado ao fórum social de Barcelona lançado em 2000, com os anos seguintes a registarem um nível progressivamente mais elevado de contestação, culminando em 2011, no auge da Grande Recessão, com 329 eventos de protesto registados, em que o movimento dos "Indignados" ganha relevância. Tal como em Portugal, os anos que se seguiram ao pico da contestação contra a austeridade foram marcados por uma desmobilização substancial, que poderemos atribuir à transferência das reivindicações efetuadas nas ruas para os novos partidos políticos, como o Podemos e as novas plataformas municipais. O último ano considerado mostra uma retoma do número de eventos de protesto, que pode ser associada à atuação dos movimentos independentistas da Catalunha e à resistência a estes em todo o país (Romanos, 2017; Romanos e Sádaba, no prelo).

A Grande Recessão constitui, assim, um marco na mobilização tanto em Portugal como em Espanha, correspondendo ao período com maior número de eventos de protesto. Mas há diferenças significativas entre os dois países. Portugal apresenta um padrão estável de protesto (com ligeiros sinais de declínio) entre 2000 e 2011, que não encontra correspondência no caso espanhol, onde o número de eventos de protesto oscila de forma mais expressiva. Após o intenso ciclo de protestos antiausteridade, os níveis de protesto diminuem significativamente nos dois lados da fronteira, havendo um efeito de desmobilização do rescaldo da crise, mas com uma tendência para crescer significativamente, mais pronunciada em Espanha no último ano analisado.

É assim possível identificar de forma clara diferentes períodos de protesto nos dois países (figura 2). Foi registado um total de 1629 eventos de protesto em Portugal (55\%) entre 2000 e 2008, enquanto no primeiro período espanhol (2000-2005) se verificaram 1665 ocorrências (31\%). Em ambos os países, o segundo período é o de mais 


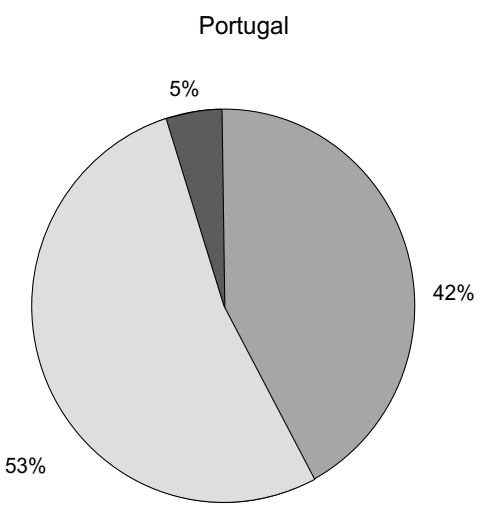

$\square$ 2000-2008 $\square$ 2009-2012 $\square$ 2013-2019

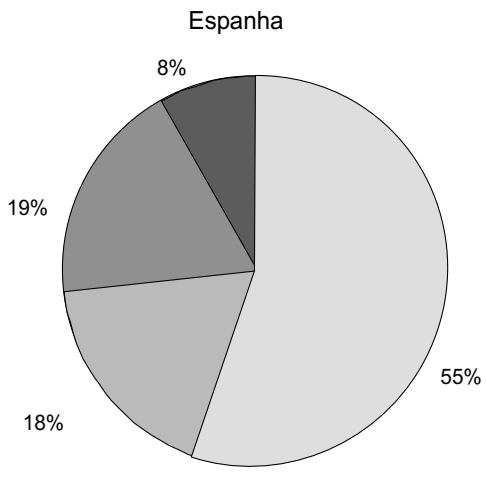

$\square$ 2000-2005 $\square$ 2006-2011 $\square$ 2012-2016

Figura 2 Períodos de protesto em Portugal e Espanha

Fonte: Disdem; elaboração própria.

intensa mobilização (com 762 episódios em Portugal entre 2009 e 2012, o que corresponde a $23 \%$ do total, e 1422 em Espanha entre 2006 e 2011 - 37\% do total), seguido de um período de desmobilização que começou após 2012 em Portugal e 2011 no país vizinho (555 eventos - ou 22\% - entre 2013 e 2017 em Portugal, e 1029 - ou $26 \%$ - entre 2012 e 2016 em Espanha). Por fim, e devido ao importante aumento dos protestos no último ano da série em Espanha, 2017 pode ser considerado o início de um quarto período, com 244 ocorrências que correspondem a $6 \%$ do total da mobilização. Para o caso português, o padrão da mobilização sugere que não é o aumento da contestação durante a crise financeira e a Grande Recessão que representa a exceção, mas sim os anos que se lhe seguiram.

Também é possível correlacionar estes resultados com a evolução dos tipos de governo nos dois países. Em Espanha, o baixo volume de protestos entre $2000 \mathrm{e}$ 2004 coincide com um governo de direita, o do Partido Popular (PP), liderado pelo primeiro-ministro José María Aznar, havendo, por outro lado, um aumento dos protestos durante o governo de esquerda que se lhe seguiu, do Partido Socialista Obrero Español (PSOE), de José Luis Rodríguez Zapatero, entre 2005 e 2011. Seguiu-se outro período de declínio do protesto (com exceção de 2012, ainda parte do intenso ciclo de protestos antiausteridade), coincidindo, uma vez mais, com o primeiro governo do PP, liderado por Mariano Rajoy (2011-2015), seguido de uma tendência para o aumento do nível de protesto nos anos subsequentes (2016-2017), correspondendo ao segundo mandato de Rajoy.

Pelo contrário, em Portugal, a mobilização popular parece ter evoluído independentemente da cor partidária do governo, como se vê no primeiro período aqui analisado, 2000-2008, correspondendo tanto a governos do Partido Socialista (PS) como do Partido Social Democrata (PSD). O ligeiro declínio nos eventos de 
protesto no período que se segue (2009-2011) corresponde ao governo do PS liderado por José Sócrates, enquanto o maior pico de protestos (2012) e os anos seguintes de decréscimo da mobilização (2013-2015) correspondem ao governo de coligação de direita do PSD e Partido Popular (PP). Por fim, no primeiro ano do governo de minoria socialista (2016) registou-se a mais baixa mobilização durante todo o período em análise, com tendência para aumentar, ainda que ligeiramente, a partir de 2017, sempre em níveis dos mais baixos de todo o período considerado.

Os ciclos de protesto em Espanha parecem assim estar muito mais ligados aos ciclos de formação de governo, com declínio dos protestos durante os governos de direita e aumento quando o PSOE assume o poder. Esta tendência poderá eventualmente ser atribuída à existência de uma mobilização de teor conservador em Espanha, uma vez que os protestos parecem intensificar-se contra os governos de centro-esquerda. Ou então, inversamente, a um cenário de maior competitividade entre partidos políticos e movimentos sociais à esquerda, que se acentuaria cada vez que o PSOE está no poder. Novos partidos como o Podemos e as suas filiais locais, os partidos políticos regionais e o movimento sindical aproveitariam assim o mandato governativo do PSOE como uma oportunidade política. Existiria assim uma perceção da sociedade civil espanhola de que os governos de esquerda seriam mais recetivos às reivindicações dos cidadãos, o que resultaria numa maior capacidade de promover eventos de protesto durante o tempo em que estes estão no poder. ${ }^{3}$ Os dois últimos anos (2016-2017), contudo, constituem uma exceção, com o aumento dos protestos durante um governo de direita.

Em contrapartida, os ciclos de protestos em Portugal parecem ser independentes do tipo de governo, uma vez que os dados mostram tanto picos altos como baixos na mobilização durante governos de direita e de esquerda. Isso aponta para a existência de uma sociedade civil eventualmente mais independente dos principais partidos presentes no governo, e para o facto de uma significativa parte dos protestos estar ligada a partidos mais à esquerda ( $\mathrm{PCP} \mathrm{e} \mathrm{BE),} \mathrm{que} \mathrm{nunca} \mathrm{fizeram} \mathrm{parte} \mathrm{de} \mathrm{uma} \mathrm{solução} \mathrm{do}$ governo e cuja relação com qualquer tipo de governo central, seja do centro-esquerda ou do centro-direita, é geralmente antagonista. Isto é confirmado pelo declínio sem precedentes dos protestos a partir das eleições de 2015. A mais baixa mobilização no país ocorreu durante a solução governativa de esquerda liderada pelo PS a partir de 2015, que foi apoiada pelos dois partidos da esquerda radical.

Outra variável importante para avaliar a magnitude dos protestos é o total de participantes ao longo deste período. ${ }^{4}$ Não é surpreendente o facto de Espanha ter registado um maior número de participantes em todos os anos da série, exceto em 2008 e 2010, quando os protestos em Portugal contaram com o maior número de participantes, tendo 2008 registado uma participação excecionalmente baixa em Espanha, enquanto que em Portugal ocorreu uma greve geral com cerca de $3 \mathrm{mi}$ lhões de participantes. Esse foi, portanto, o ano em que se registou uma maior

3 Sobre o conceito de estrutura de oportunidades políticas e as dinâmicas entre partidos e movimentos sociais da esquerda $v d$. Kriesi et al. (1995). Para uma crítica e revisão $v d$. Amenta e Halfmann (2012) e Goodwin e Jasper (2012).

4 O número de participantes não é referido em todos os eventos de protesto

SOCIOLOGIA, PROBLEMAS E PRÁTICAS, n.ำ 97, 2021, pp. 9-33. DOI: 10.7458/SPP20219724909 


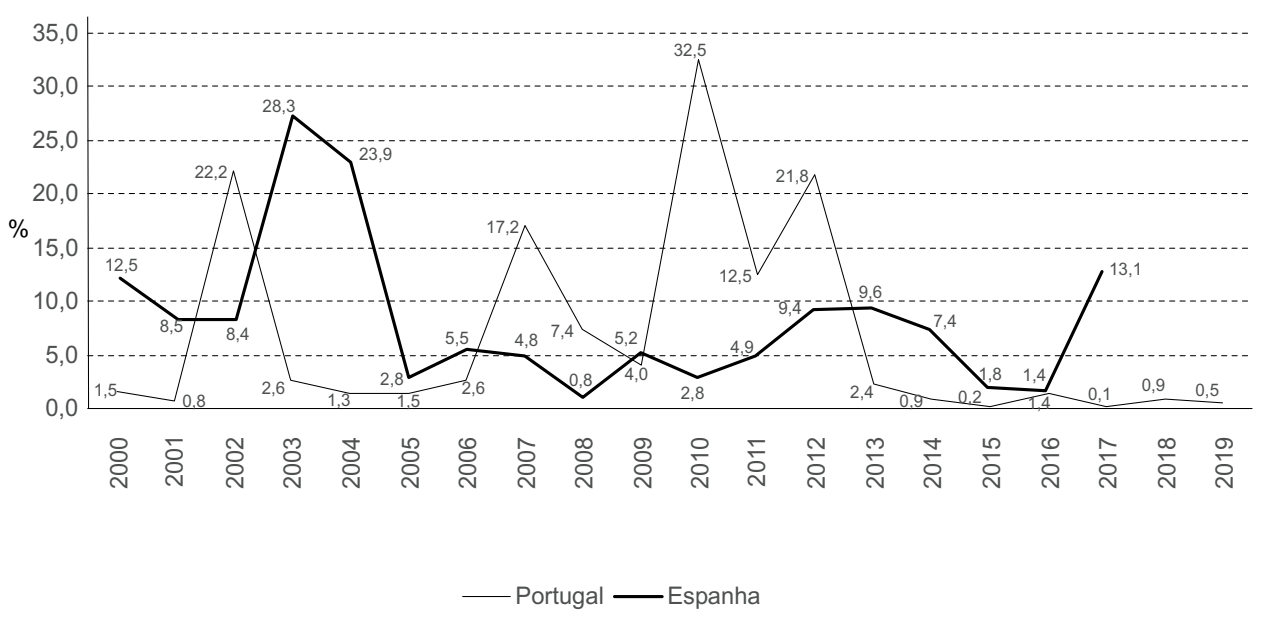

Figura 3 Percentagem de participantes (em relação ao total da população) nos protestos em Portugal e em Espanha

Fontes: Disdem; Pordata, Portugal:

https://www.pordata.pt/Municipios/Popula\%C3\%A7\%C3\%A3o+residente+total+e+por+grandes+grupos+et\%C3\% A1rios-390, e Instituto Nacional de Estadística, Espanha:

http://www.ine.es/dyngs/INEbase/en/categoria.htm?c=Estadistica_P\&cid=1254735572981; elaboração própria.

participação em Portugal. O ano de 2002 teve igualmente uma elevada participação em eventos de protesto, em virtude de uma muito participada greve geral contra as reformas laborais do governo e pela contestação à intervenção no Iraque, que teve igualmente uma forte mobilização antiausteridade.

Considerando os períodos de protesto identificados acima, fica claro que os três anos de mobilização antiausteridade constituem o auge da participação da população em eventos de protesto em Portugal. E o declínio acentuado no número de protestos a partir de 2013 e até 2017 corresponde à maior diminuição de número de participantes em todo o período considerado. Em Espanha, por outro lado, é nos primeiros seis anos da série que se assiste à mais elevada participação em eventos de protesto, ligada a temas de teor mais consensual trazidos para o espaço público, como a contestação à guerra no Iraque, a proteção do meio ambiente e a condenação do terrorismo. Em Espanha, um número elevado de participantes verificou-se em 2003 e 2004, devido à intensa contestação ao apoio do governo à intervenção norte-americana no Iraque, aos protestos que ocorreram em todo o país relacionados com o naufrágio do petroleiro Prestige na Galiza e às várias manifestações de repúdio aos atentados terroristas de 11 de março de 2004 em Madrid (Romanos e Sádaba, no prelo).

De forma a clarificar estas tendências, foi calculada, face ao total da população de cada país, a percentagem anual de participantes em eventos de protesto (figura 3). Portugal e Espanha têm percentagens quase iguais, com Espanha ligeiramente acima $(8,6 \%$ e $7,6 \%$, respetivamente). Contudo, o momento com maior participação da população em eventos de protesto, em todo o período em análise, 
ocorreu em Portugal logo no início do ciclo de austeridade (2010-2014), no ano de 2010, com 32,5\%. Mais, durante o período que antecede a Grande Recessão e durante a implementação do programa de austeridade, entre 2007 e 2012, Portugal tem sempre maiores percentagens da população em eventos de protesto do que Espanha. Deste ponto de vista, em Portugal o ciclo de protesto antiausteridade corresponde ao momento de maior participação popular, enquanto que em Espanha há uma mais fraca mobilização neste período (cerca de 10\% da população em 2012 e 2013, mas significativamente mais baixa nos outros anos). Ao invés, é em 2003 e 2004 que Espanha atinge o pico da mobilização (quase 30\% em 2003), correspondendo às manifestações contra a guerra no Iraque e no seguimento dos atentados terroristas em Madrid de 2004 e da crise política que se seguiu.

\section{Os participantes dos protestos}

Esta secção apresenta uma análise centrada nas categorias sociais de participantes presentes nos eventos de protesto nos dois países (figura 4). No caso de Portugal, os trabalhadores (que incluem funcionários públicos, trabalhadores sem filiação, trabalhadores de empresas privadas, agricultores e trabalhadores agrícolas, e trabalhadores precários) representam a categoria social mais importante, totalizando $40 \%$ dos participantes individuais.

Outras categorias relevantes são o cidadão comum $(24,5 \%)$ e os ativistas (somando ativistas sindicais, com $2,4 \%$ e ativistas por uma causa, com 8,4\%), totalizando $10,8 \%$, assim como os estudantes (universitários e do ensino secundário), presentes em $7,9 \%$ dos protestos.

As primeiras duas categorias de participantes são também importantes em Espanha - ainda que haja uma menor relevância dos trabalhadores, que representam $19,2 \%$ dos participantes nos protestos. Os cidadãos comuns correspondem a $28,1 \%$ dos participantes, cerca de $4 \%$ acima do valor em Portugal.

Os ativistas estão mais presentes nas mobilizações em Espanha, totalizando $19,1 \%$ dos participantes (ativistas por uma causa representam 15,3\% e ativistas sindicais $3,8 \%$ ), e verificam-se igualmente mobilizações dos jovens, particularmente estudantes universitários $(3,8 \%)$, jovens que protestam independentemente da sua ligação ao sistema de ensino (2,9\%), assim como as famílias e os imigrantes (Romanos e Sádaba, no prelo).

O protesto e a ação coletiva em Portugal continuam assim a estar muito ligados ao mundo do trabalho, o que vai ao encontro da investigação realizada sobre sociedade civil e protesto neste país e revela a importância dos sindicatos na esfera pública, tema a que este artigo voltará (Accornero e Ramos Pinto, 2015; Fernandes, 2014 e 2017). Esta tendência é também reveladora da importância de questões de classe e das categorias socioeconómicas no protesto em Portugal, assim como do próprio estado, uma vez que são os funcionários públicos e os trabalhadores que mais se mobilizam, quer para contestar políticas do próprio estado quer para apoiar revindicações dos trabalhadores do setor privado. O estado é também um fator importante no que se refere ao protesto dos jovens, uma vez que estes se mobilizam 


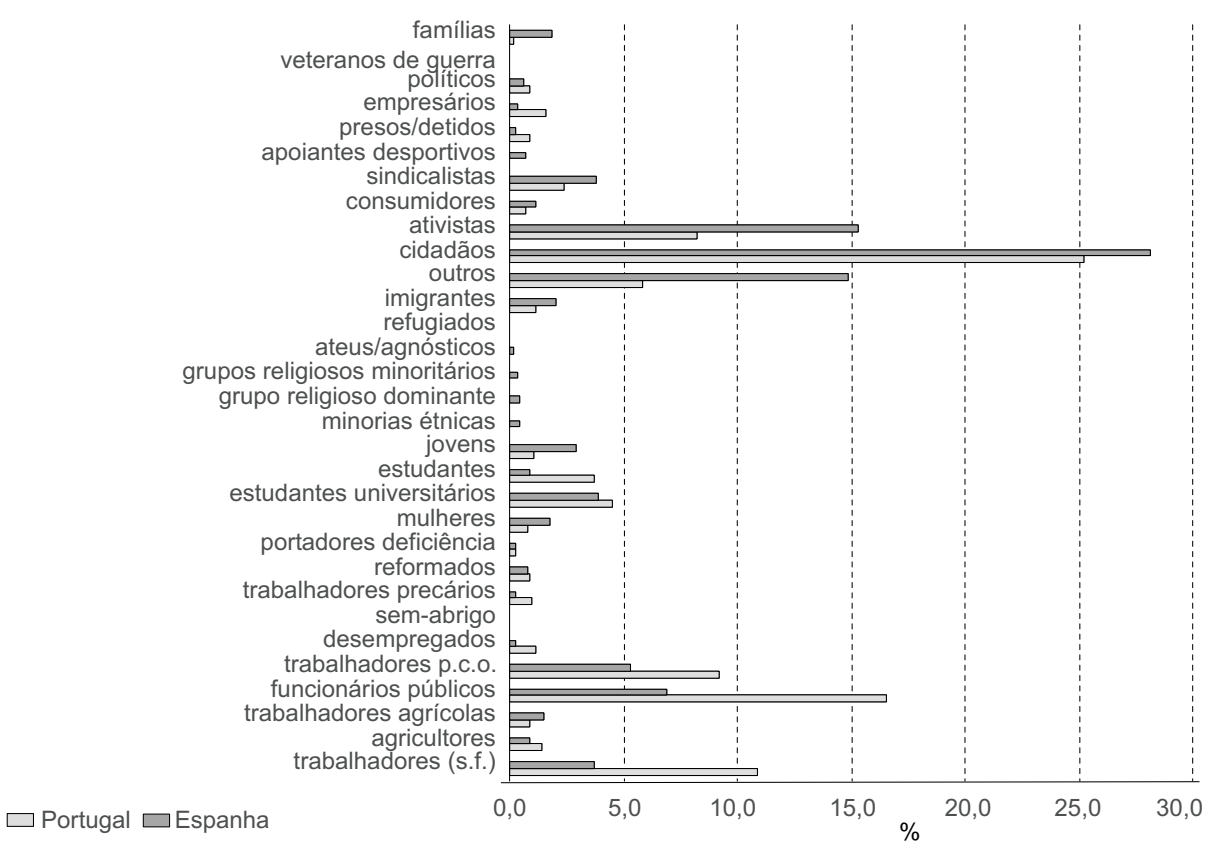

Figura 4 Participantes nos protestos em Portugal e Espanha

Fonte: Disdem; elaboração própria.

sobretudo no contexto do sistema de ensino público (universidades e escolas).

Esse não é o caso de Espanha, uma vez que as categorias de ativista e de cidadão em geral são tão importantes como as categorias socioeconómicas, e onde os jovens tendem a protestar à margem do sistema de ensino. Além disso, a presença de categorias identitárias, como mulheres $(1,7 \%)$, famílias $(1,9 \%)$ ou imigrantes $(2 \%)$ é mais relevante do que em Portugal. É, assim, possível afirmar que o protesto em Portugal é mais tradicional e baseado em questões de classe, enquanto Espanha é uma arena que reflete clivagens relacionadas com os novos movimentos sociais (ecologia, feminismo, direitos dos migrantes). A maior presença de ativistas e líderes sindicais em Espanha indica igualmente uma maior profissionalização dos protestos.

\section{Os organizadores do protesto}

A maioria dos eventos de protesto nos dois países tem um organizador identificado, responsável pela mobilização dos participantes - 63,5\% em Portugal e 57,6\% em Espanha (figura 5). Em Portugal, os sindicatos continuam a ser o mais importante organizador de protestos, responsáveis por mais de metade de todos os eventos com um organizador identificado $(50,2 \%)$, seguidos das iniciativas cidadãs, com 21,6\%. Considerados em conjunto, estes dois atores são responsáveis por 


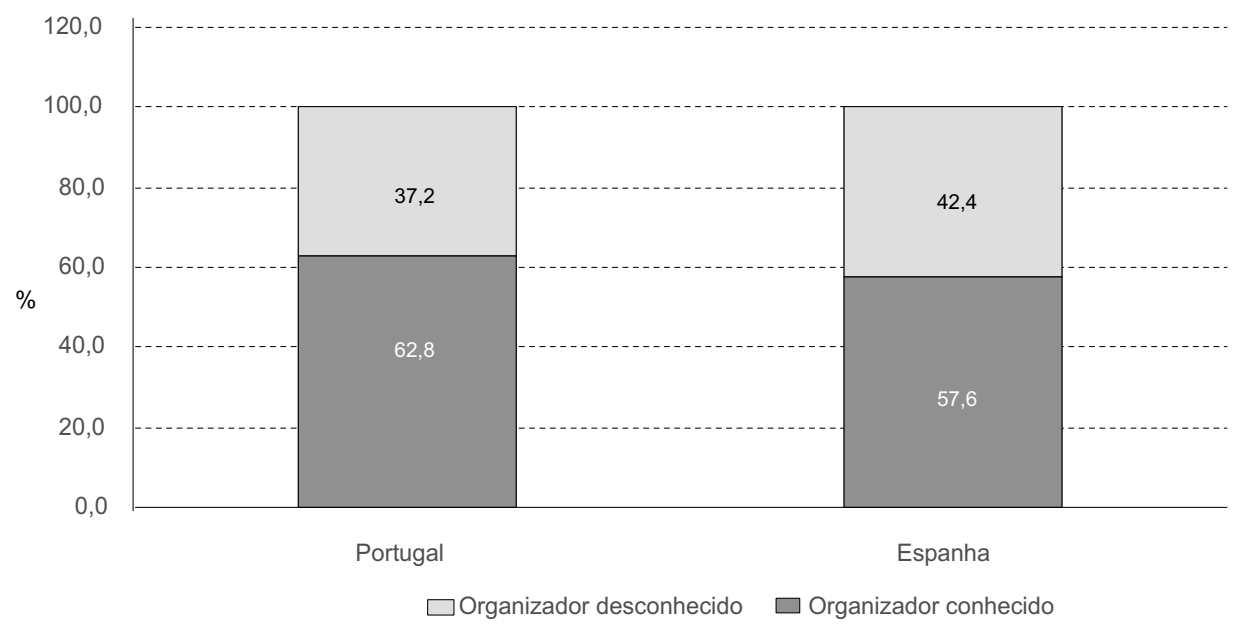

Figura 5 Organizadores identificados dos protestos em Portugal e Espanha

Fonte: Disdem; elaboração própria.

quase três quartos dos protestos no país, seguindo-se outros atores, como as organizações de estudantes do ensino secundário ou superior $(6,8 \%)$ e as organizações profissionais (5,2\%) (figura 6).

Em Espanha, e apesar de os sindicatos serem também a mais importante categoria de organizadores de protestos, a sua importância é significativamente mais reduzida ( $21,5 \%$ dos episódios), seguidos, quase com a mesma importância, pelas iniciativas cidadãs $(20,6 \%)$. Os dados apontam assim para uma maior relevância dos sindicatos em Portugal, que detêm uma capacidade mobilizadora duas vezes superior à dos seus homólogos em Espanha, mas também das iniciativas cidadãs, que é ligeiramente superior.

Os partidos políticos espanhóis, contudo, são muito mais ativos do que os seus correspondentes portugueses na organização dos protestos $(12,1 \%$ e 3,3\%, respetivamente). O mesmo acontece com as organizações de direitos humanos/pacifistas $(8,6 \%$ e $0,5 \%$ ) e organizações ambientalistas ( $4,2 \%$ e 2,2\%). Relevantes são também as organizações profissionais e de estudantes em Espanha, responsáveis, respetivamente, por $3,3 \%$ e $3,2 \%$ do total de protestos com um organizador identificado, seguidas de perto por organizações de jovens sem ligação às instituições ou ao sistema educativo $(2,8 \%)$. Em conjunto, estas organizações são responsáveis por três quartos dos eventos de protesto realizados em Espanha com um promotor identificado. Outras diferenças a destacar são o papel desempenhado em Espanha pelas organizações contra as execuções de hipotecas e despejos $(2,9 \%)$ e o facto de os governos locais emergirem como organizadores de protestos nos dois países, mas com uma percentagem mais elevada em Portugal do que em Espanha (2,2\% contra 1,6\%) (Romanos e Sádaba, no prelo).

Estes dados apontam para uma sociedade civil mais pluralista, composta por causas identitárias diversas (pais, ambientalistas, mulheres, imigrantes, religião, 
Figura 6 Organizadores de protestos em Portugal e Espanha

Fonte: Disdem; elaboração própria.

direitos humanos, etc.) no caso espanhol, enquanto que em Portugal são mais relevantes os atores tradicionais da sociedade civil, representativos de reivindicações e clivagens de tipo socioeconómico e relacionadas com o acesso à educação (sindicatos, organizações profissionais e associações de estudantes). As iniciativas cidadãs e o governo local são igualmente relevantes em Portugal, embora com percentagens muito menos significativas.

Os partidos políticos são também mais mobilizadores em Espanha, refletindo a emergência dos novos partidos à esquerda, como o Podemos, eles próprios emanações de movimentos sociais, assim como o papel tradicional dos partidos nacionalistas e regionalistas na organização dos protestos desde a fundação da democracia. Vale a pena sublinhar que a ausência de partidos políticos na organização dos protestos no caso português obscurece a influência do Partido Comunista sobre os sindicatos, particularmente sobre a confederação intersindical CGTP e os sindicatos que lhe são afetos.

\section{Campanhas e coligações}

A formação de coligações e a organização de campanhas entre movimentos e aliados vários, que podem incluir quer outros movimentos sociais, quer atores institucionais 


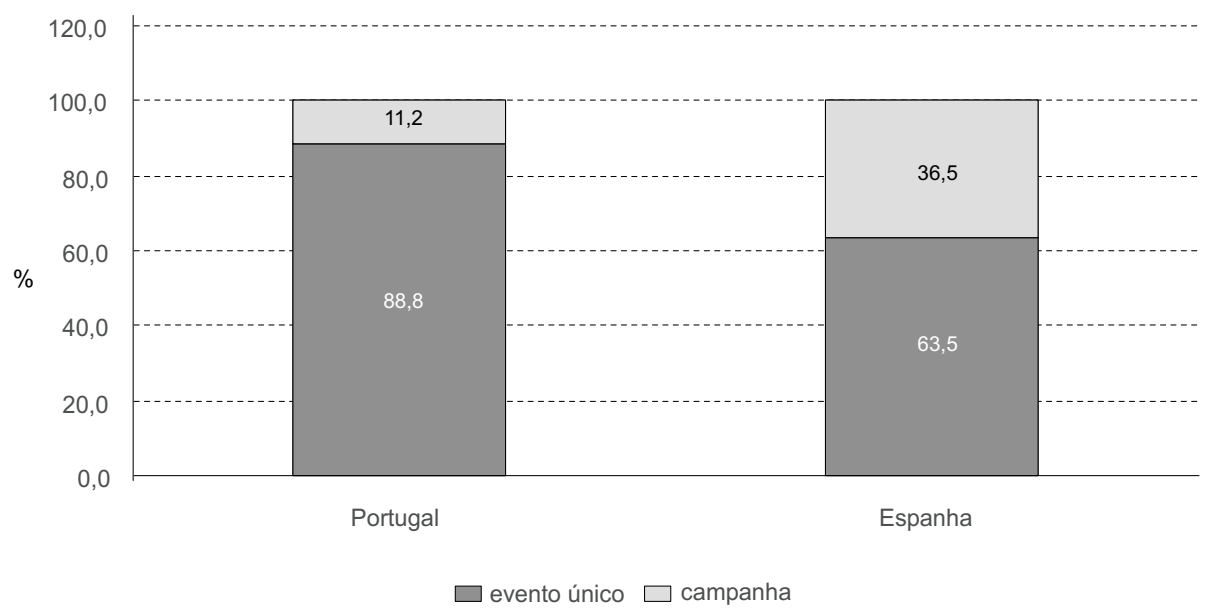

Figura 7 Campanhas de protesto em Portugal e Espanha Fonte: Disdem; elaboração própria.

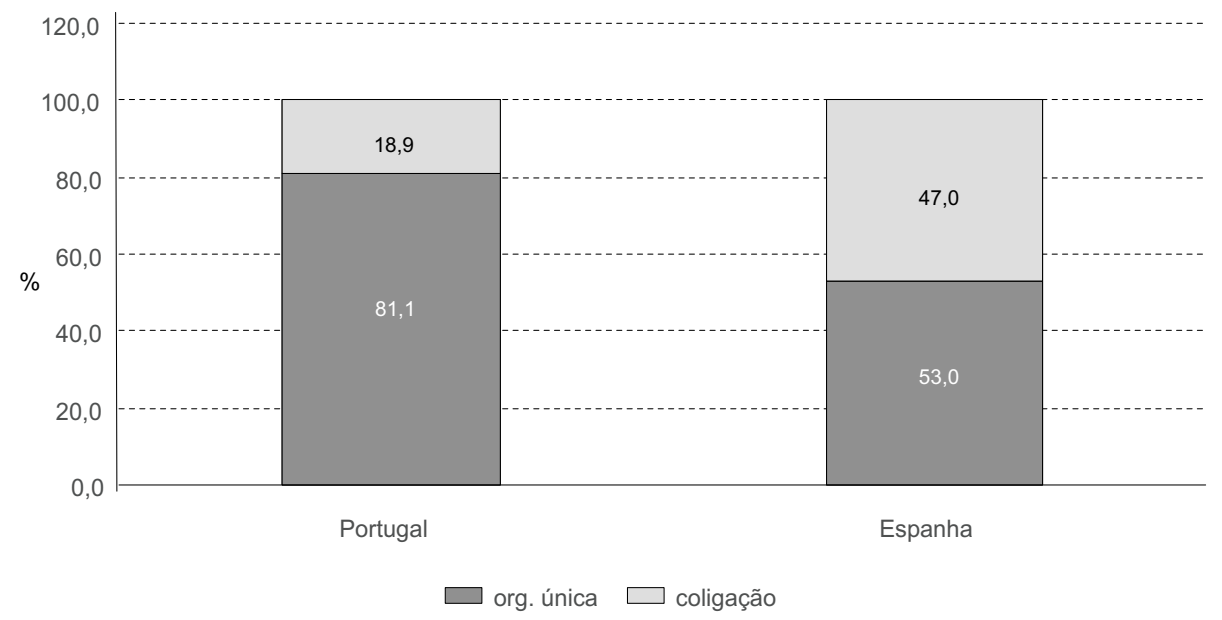

Figura 8 Coligações de organizadores de protestos em Espanha (2000-2017) e Portugal (2000-2019) Fonte: Disdem; elaboração própria.

(partidos, grupos parlamentares, juízes, etc.), é um indicador da institucionalização da arena do protesto e da autonomia dos movimentos sociais (Weiss, 2006:3-4). A informação relativa a campanhas de protesto (figura 7), deixa claro que campanhas de protesto prolongadas são mais frequentes em Espanha do que em Portugal (36,5\% contra $11,1 \%$ ). Embora em ambos os países os protestos isolados sejam a norma, essa 
proporção é muito superior em Portugal relativamente a Espanha (88,9\% e 63,5\%, respetivamente).

Os protestos em Espanha têm também uma maior percentagem de coligações de organizadores (47\%, por oposição a $20,1 \%$ em Portugal) (figura 8 ), o que indica uma maior institucionalização do protesto. Estes dados confirmam assim um maior nível de organização e uma forma mais complexa de ação coletiva em Espanha, onde os movimentos sociais mais facilmente promovem ações conjuntas.

\section{Os aliados do protesto}

A disponibilidade de aliados é crucial para a emergência, mas sobretudo para o impacto dos movimentos sociais, ao providenciar recursos essenciais à ação coletiva, mas também reconhecimento político e legitimidade moral (Goodwin, 2012: 291-292). A figura 9 mostra como há maior prevalência de aliados em Espanha (20,8\%) do que em Portugal (12,5\%). Uma vez mais, a maior oferta de aliados dos movimentos sociais em Espanha aponta para a maior coordenação e institucionalização dos protestos neste país.

Os dois países, contudo, partilham semelhanças no que se refere à tipologia dos aliados de protesto, uma vez que em ambos os casos são os partidos políticos (34,2\% em Portugal e 46,4\% em Espanha), os sindicatos (23,4\% em Portugal e 18,6\% em Espanha) e, com uma percentagem muito inferior, as iniciativas de cidadãos (4,7\% em Portugal e 6,4\% em Espanha) que constituem os mais importantes atores. Contrariamente ao caso português, em que os sindicatos são os mais frequentes aliados dos movimentos de protesto, em Espanha esse papel cabe mais aos partidos e às iniciativas cidadãs (figura 10).

Outra diferença significativa está relacionada com a posição dos governos locais, que atuam como o segundo mais significativo aliado do protesto no caso de Portugal (24,9\%), sendo a sua atuação em Espanha nitidamente menos significativa (4\%). Este dado parece assim confirmar investigação recente que mostra como o poder local em Portugal não só é mais aberto à sociedade civil, mas também é estruturado em normas, muitas vezes informais, de democracia participativa e inclusiva (Fernandes e Branco, 2017; Magalhães, 2017).

Estes dados demonstram, uma vez mais, a importância dos sindicatos em Portugal para a organização dos protestos, onde estes são não apenas organizadores, mas também, frequentemente, aliados em outros eventos de protesto. Indicam, além disso, que, em Portugal, o próprio estado atua como aliado de protesto, particularmente ao nível local, fornecendo recursos, voz, e acesso e reconhecimento institucional. Este facto levanta também a questão de se saber se os próprios governos locais constituem, eles próprios, uma estrutura democrática nacional de tipo "desobediente". Na verdade, uma importante organização na mobilização dos protestos em Portugal durante o ciclo de austeridade foi a Associação Nacional de Freguesias, que representa mais de 4000 unidades políticas e que a 31 de março de 2012 conseguiu mobilizar mais de 150.000 cidadãos nas ruas contra o plano de reorganização do poder local do governo PSD-PP (Fernandes, 2017). 


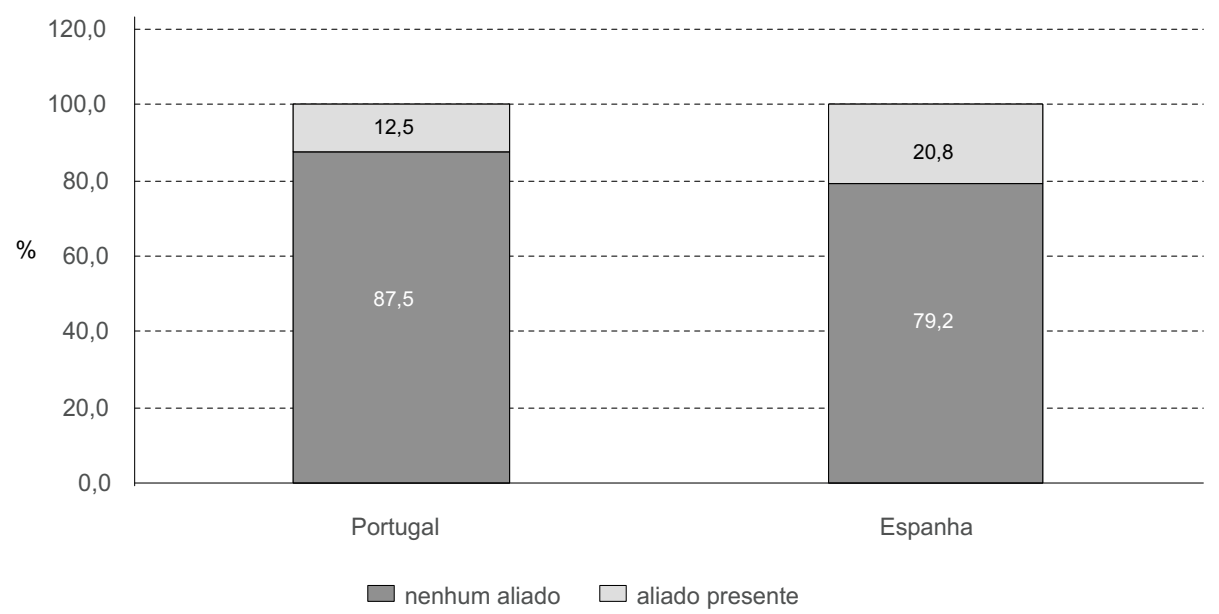

Figura 9 Presença de aliados de protesto em Portugal e Espanha

Fonte: Disdem; elaboração própria.

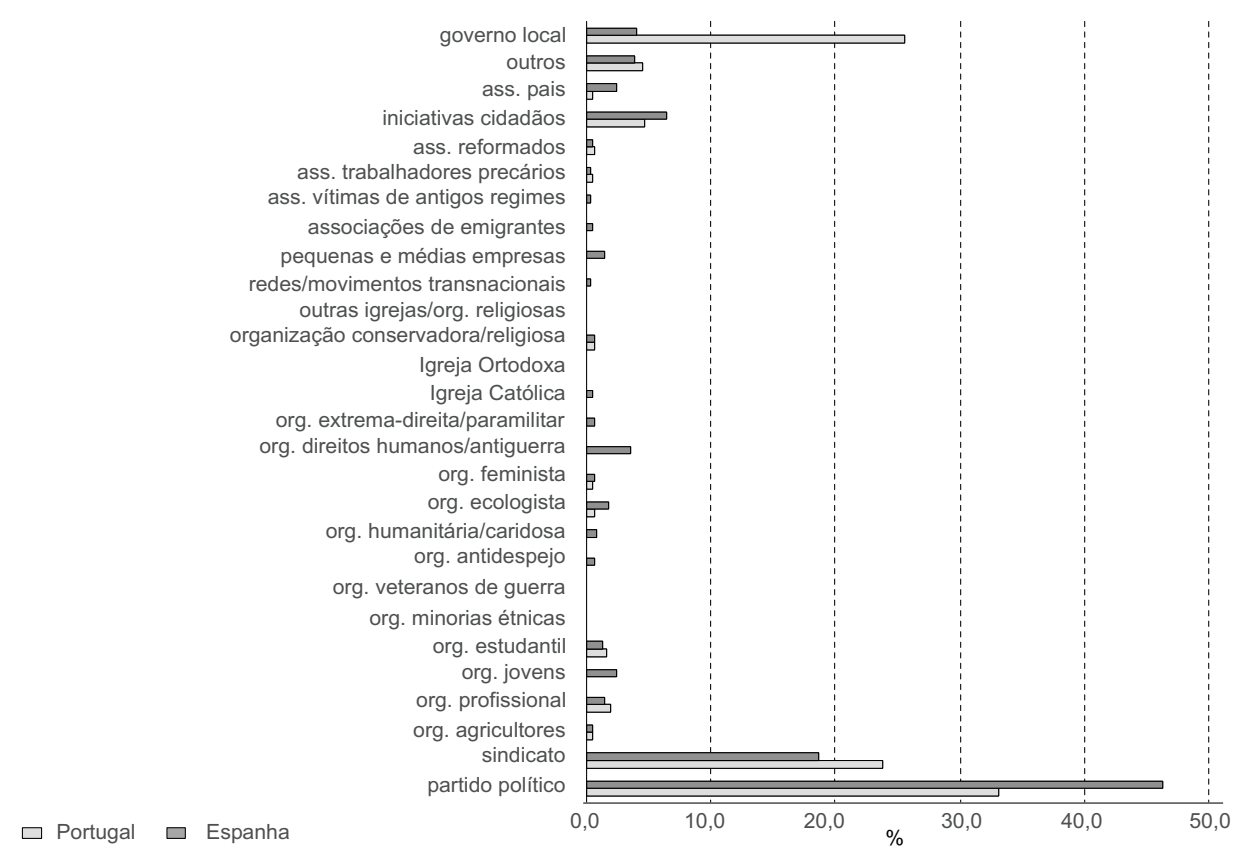

Figura 10 Aliados de protesto em Espanha (2000-2017) e Portugal (2000-2019) Fonte: Disdem; elaboração própria. 
Outras diferenças, ainda que com percentagens menores, estão relacionadas com a menor relevância das organizações profissionais, de estudantes universitários ou do ensino secundário e das organizações ambientais em Portugal. Em Espanha são frequentemente as organizações de jovens, de pais ou outras contra a guerra ou pela defesa dos direitos humanos que atuam como aliados do protesto, o que demonstra quer a maior importância da atividade de grupos identitários e das causas dos novos movimentos sociais, quer dos atores mais conservadores da sociedade civil espanhola, como as organizações de pais e de interesses privados (Romanos e Sádaba, no prelo).

\section{Reivindicações}

As reivindicações dos participantes em eventos de protesto são um indicador aproximado das clivagens e linhas de rutura que dividem uma sociedade. A figura 11 confirma que as questões relacionadas com o trabalho são mais importantes em Portugal, sendo os direitos dos trabalhadores a reivindicação mais significativa $(28,5 \%)$, seguida da educação $(9,5 \%)$ e da contestação face ao desemprego $(8,6 \%)$. A contestação a leis e políticas específicas (5,7\%), questões relacionadas com o planeamento urbano $(5,5 \%)$ e com cortes nos serviços públicos $(5,4 \%)$ vêm a seguir. Quando consideradas em conjunto, estas questões correspondem a mais de $60 \%$ de todas as reivindicações expressas nos eventos de protesto entre 2000 e 2019.

Em Espanha, e apesar de as questões relacionadas com o trabalho serem uma reivindicação importante, são-no numa dimensão mais reduzida. Apenas 7,8\% estão relacionadas com os direitos dos trabalhadores e 4,9\% com o desemprego, apesar de níveis de desemprego tradicionalmente mais elevados do que em Portugal. De facto, a reivindicação mais premente nos protestos espanhóis diz respeito aos direitos civis (10,6\% e 1,9\% em Portugal), com as exigências de autodeterminação e independência ( $7 \%$, e inexistentes em Portugal) e a contestação a leis e políticas específicas $(6,8 \%)$, a partidos e a políticos $(5,1 \%$ e $0,8 \%$ em Portugal) e a cortes nos serviços públicos $(4,4 \%)$ a aparecerem logo a seguir. Outras semelhanças entre os dois países podem ser encontradas na mobilização relativa a cortes nos serviços públicos e a leis específicas, bem como, ainda que numa percentagem muito menor, nos protestos motivados por queixas relacionadas com questões ambientais $(2,5 \%$ em Espanha e 2,5\% em Portugal) ou com insatisfação com o sistema judicial (2\% em Espanha e 1,5\% em Portugal).

Embora a distinção mais significativa entre os dois países esteja relacionada com a importância das questões relativas ao trabalho, encontram-se diferenças igualmente nas reivindicações relativas aos serviços públicos disponibilizados pelo estado em Portugal, particularmente na educação (9,5\% e 4\% em Espanha), planeamento urbano (5,5\% e 0,8\% em Espanha) e saúde (4,2\% e 2,1\% em Espanha). No caso espanhol, verifica-se uma maior diversidade de reivindicações que ou são pouco significativas ou não estão sequer representadas em Portugal, como é o caso dos protestos antiterrorismo (3,9\%), anticorrupção (2,4\% e $0,04 \%$, respetivamente), de oposição a instituições internacionais (2,2\% e 0,3\%) ou contra o próprio regime 


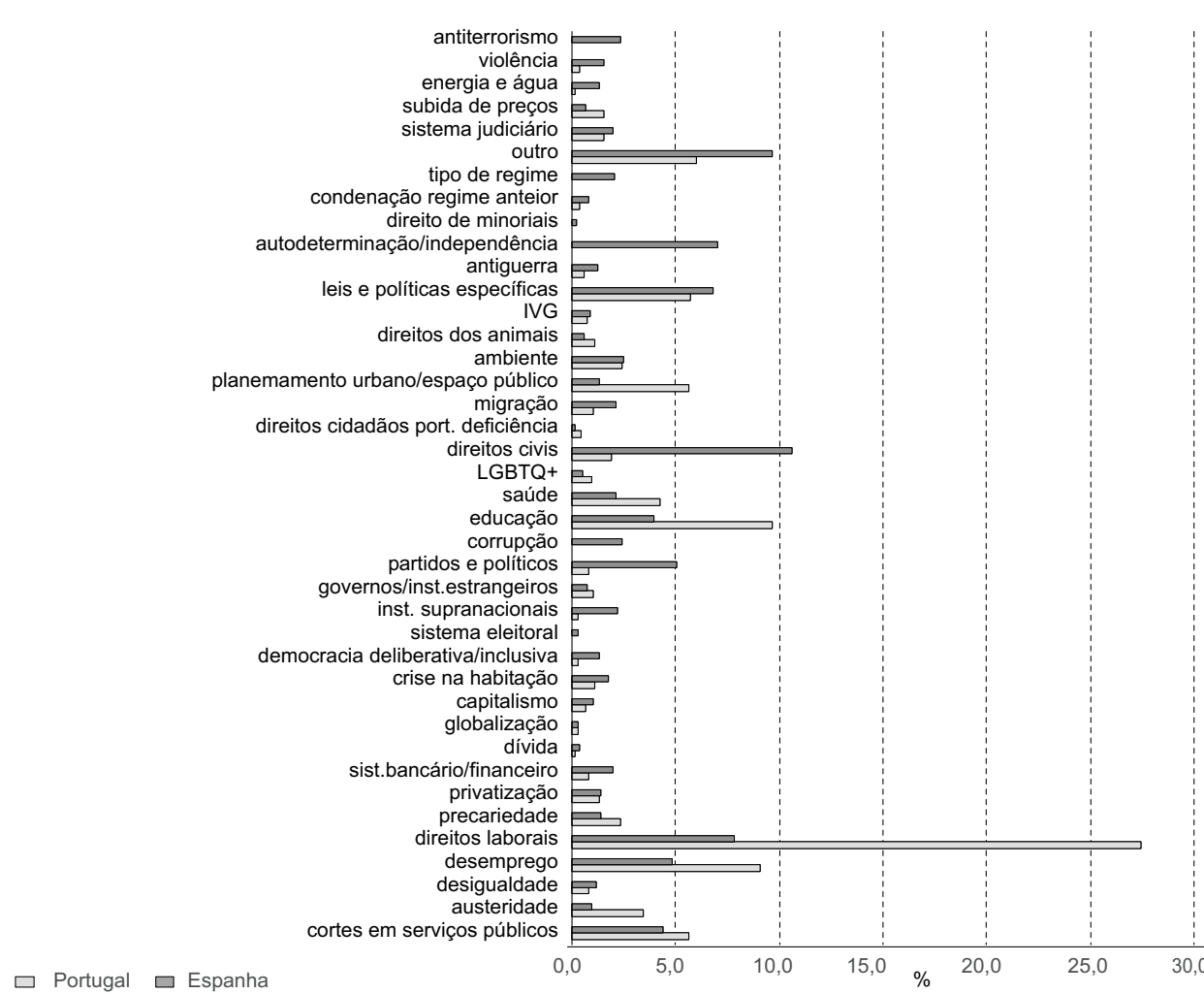

Figura 11 Reivindicações nos protestos em Portugal e Espanha

Fonte: Disdem; elaboração própria.

político, contestado sobretudo em protestos antimonárquicos $(2,1 \%$ e $0,4 \%$ em Portugal). Questões relacionadas com a imigração (2,1\% contra 1,1\%), o sistema financeiro $(2 \%$ vs. $0,8 \%)$ e a crise imobiliária $(1,8 \%$ e $1,2 \%)$ são também superiores em Espanha.

A questão da precariedade, uma vez mais relacionada com o trabalho, é uma reivindicação mais importante em Portugal do que em Espanha e foi principalmente expressa durante o ciclo de protestos antiausteridade (2,5\% e 1,4\%). É importante também acrescentar que reivindicações relacionadas com o trabalho articuladas por funcionários públicos em Portugal são frequentemente associadas com outras, como a provisão de serviços públicos. Funcionários públicos, principalmente professores e profissionais da saúde, por exemplo, juntam às reivindicações sobre os direitos de trabalhadores as exigências relativas ao direito da população a serviços públicos de educação e de saúde de boa qualidade. Estes resultados, mais uma vez, apontam para o facto de o estado, em Portugal, ser sobretudo alvo de protesto na sua qualidade de fornecedor de serviços públicos e garante dos direitos dos cidadãos (particularmente dos direitos laborais, mas não só), enquanto que, em 
Espanha, o estado e as suas instituições são alvo de reivindicações sobretudo ligadas a direitos civis, à qualidade e tipo de regime democrático, assim como de exigências nacionalistas e regionalistas. Assim, no caso espanhol, grande parte dos protestos é dirigida contra o estado e o regime enquanto tais.

\section{Repertórios de protesto}

Os repertórios de protesto são predisposições culturais implícitas que determinam as formas de agir e as táticas consideradas aceitáveis e racionais em momentos de ação coletiva (Tarrow, 1995: 90-91). Mais uma vez, a tendência para uma maior diversidade no protesto espanhol está também presente quando considerados os repertórios de protesto (figura 12). Em Portugal há sobretudo uma propensão para a ocorrência de manifestações $(39,1 \%)$, greves $(17,1 \%)$ e marchas $(11,9 \%)$, seguidas de performances simbólicas ou artísticas (6,4\%). Estas quatro formas de ação coletiva, em conjunto, representam três quartos de todos os eventos de protesto. Em Espanha, pelo contrário, são as assembleias populares que constituem a mais importante forma de ação coletiva ( $26,8 \%)$, seguidas da exibição de cartazes e faixas $(14,4 \%)$, manifestações $(12,4 \%)$, marchas $(8,5 \%)$ e performances $(5,3 \%)$. Em conjunto, estes repertórios representam mais de dois terços do total dos protestos, enquanto as greves apenas constituem $4,3 \%$ de todas as ocorrências no país (Romanos e Sádaba, no prelo).

As semelhanças entre os dois países no que se refere aos repertórios de protesto limitam-se, assim, à ocorrência de marchas e performances simbólicas. De facto, os repertórios são bastante diferentes entre os dois países, com formas mais tradicionais de protesto a ocorrerem em Portugal (manifestações, greves - o repertório de protesto socioeconómico por excelência - , marchas e performances), às vezes complementadas com outro tipo de iniciativas, como greves de fome ( $1,7 \%$ contra $0,8 \%$ em Espanha), boicotes ( $2,2 \%$ contra $1,2 \%)$ e petições $(1,8 \%$ contra 1,2\%). Em Espanha, pelo contrário, a tendência é para se recorrer a repertórios de protesto que passam pela ocupação permanente do espaço público e que revelam uma cultura de democracia direta (assembleias populares - $26,8 \%$, acampadas $-7,5 \%$, em "outro", exibição de faixas - 14,4\%). Estes repertórios de protesto são frequentemente usados numa diversidade de temas, desde questões laborais a expressões de solidariedade ou questões locais. E durante o ciclo de protesto contra a austeridade verificou-se a sua generalização para os diversos bairros das principais cidades, associada à criação de assembleias e grupos de trabalho locais (Romanos, 2017).

Em termos de protesto disruptivo e violento, os motins e os ataques à propriedade ou a pessoas são mais frequentes em Espanha do que em Portugal, registando este país igualmente uma maior frequência de ocupações (3,4\% e 2,1\% em Espanha). Espanha mostra também uma maior incidência de bloqueios de estradas (4\%, face a 3,2\% em Portugal) e sit-ins ( $2,4 \%$ e $2 \%$ em Portugal), embora a níveis baixos e com diferenças pouco significativas face a Portugal. Isto aponta, assim, para um protesto mais disruptivo e violento em Espanha, enquanto que em Portugal os 


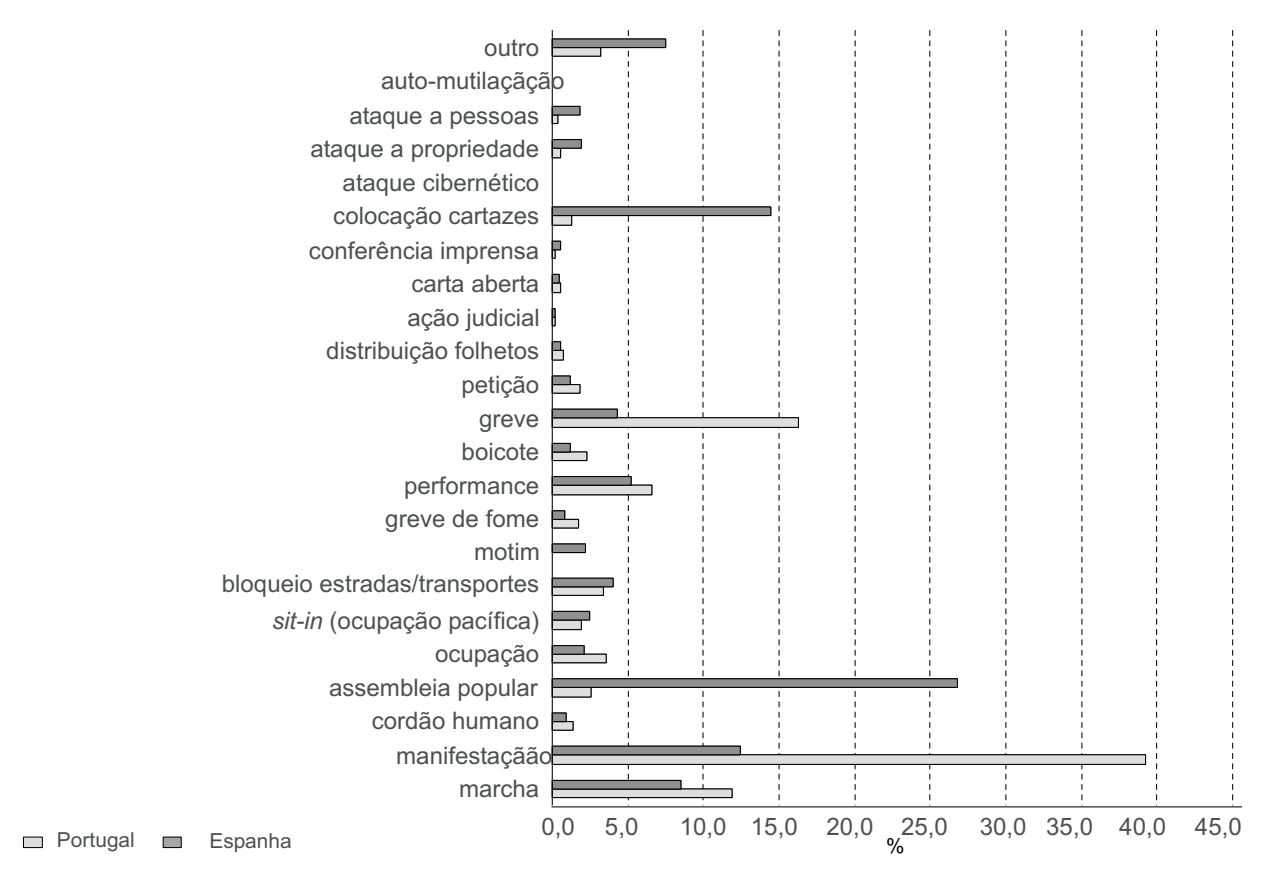

Figura 12 Repertórios de protesto em Espanha (2000-2017) e Portugal (2000-2019)

Fonte: Disdem; elaboração própria.

repertórios de protesto mais comuns tendem a ser de tipo pacífico, mesmo quando são disruptivos, como as ocupações.

\section{Conclusão}

Esta panorâmica descritiva dos ciclos e características dos protestos em Portugal e Espanha permite tirar algumas conclusões, ainda que provisórias, sobre a relação entre protesto e democracia. Do ponto de vista da institucionalização do protesto, cada país representa um modelo bastante diferente. Em termos da participação dos cidadãos em eventos de protesto, os dois países têm níveis praticamente iguais, embora Espanha esteja ligeiramente acima de Portugal (8,6\% e 7,6\%, respetivamente). Contudo, em Espanha é mais elevado o número de eventos de protesto e a sua dimensão tende também a ser maior. Em Portugal, 77,5\% dos eventos de protesto têm menos de 500 participantes, em Espanha 68,7\% têm entre 51 e 5000 participantes.

Outra diferença é o padrão temporal da mobilização da população. Em Portugal, picos bastante elevados alternam com fases de muito baixo protesto. Em Espanha, a participação da população nos protestos é mais regular, com a diferença entre picos e períodos de baixa participação a ser mais pequena. Contudo, o ano de 
maior a participação da população em todo o período em análise nos dois países ocorreu em Portugal em 2010, com a participação de 32,5\% população.

O tipo de organizações que promovem os protestos é também diferente entre os dois países. Em Portugal, essa tarefa cabe sobretudo aos sindicatos, às iniciativas cidadãs, às organizações de estudantes do ensino secundário e superior e às organizações profissionais. Embora relevantes em Espanha, estas organizações têm muito menor capacidade mobilizadora. Pelo contrário, os partidos políticos, as organizações de direitos humanos/pacifistas, as organizações ambientalistas e os movimentos contra as execuções de hipotecas e os despejos têm um papel muito mais importante. Esta pode ser a razão pela qual os anos de mobilização antiausteridade (2010-2014) constituíram o auge da participação da população em eventos de protesto em Portugal, enquanto que em Espanha foi o período entre 2000 e 2006 a ter essa característica, com uma vaga de protesto ligada a questões como a guerra no Iraque, a proteção do meio ambiente e a condenação do terrorismo.

As campanhas prolongadas e a formação de coligações são mais frequentes em Espanha do que em Portugal. E embora haja semelhanças no que se refere à tipologia dos aliados de protesto, uma vez que em ambos os casos são os partidos políticos, os sindicatos e as iniciativas de cidadãos que ocupam essa função, os sindicatos são muito mais importantes em Portugal, enquanto que os partidos políticos e as iniciativas cidadãs o são em Espanha. Uma singularidade portuguesa é também o papel desempenhado pelos governos locais, que atuam como o segundo mais significativo aliado do protesto, sendo a sua atuação em Espanha muito menos significativa.

Em termos das categorias sociais dos participantes, embora os trabalhadores, o cidadão comum, os ativistas e os jovens sejam relevantes em ambos os países, são-no menos em Espanha. Outras categorias são mais importantes neste país, como os ativistas profissionais, as mulheres, as famílias ou os imigrantes.

Em suma, visto a partir do tipo de participantes como das organizações de mobilização, a arena do protesto em Portugal é mais tradicional e estruturada em torno de questões de classe, de trabalho e relacionadas com o ensino público, enquanto que em Espanha há maior presença dos novos movimentos sociais (ecologia, feminismo, direitos dos imigrantes) ou de movimentos conservadores como de defesa da família. A sociedade civil espanhola também é mais profissionalizada, com maior presença de ativistas e uma maior propensão para a formação de coligações e campanhas conjuntas, o que pode estar na origem da maior participação nos eventos de protesto. Por outro lado, em Portugal o protesto é mais micro, o que pode ser em parte explicado pelo apoio dado pelos governos locais.

O padrão português está também associado a uma cultura de protesto mais democrática. Em termos de reivindicações e exigências veiculadas nos ciclos de protesto, são predominantes os temas socioeconómicos, eventualmente solucionáveis por políticas públicas de tipo redistributivo, como direitos dos trabalhadores, desemprego, educação e urbanismo. Em Espanha, por sua vez, há uma maior presença de temas polarizadores e que revelam fraturas no regime político, como os 
direitos civis, a corrupção, a autodeterminação e independência regionais e a condenação dos partidos, da monarquia e da classe política.

Mais ainda, os repertórios de protesto em Portugal evidenciam um nível cívico superior a Espanha. Formas de ação coletiva tradicionais, como as manifestações, as greves, as marchas e as petições são mais comuns em Portugal. Em Espanha os repertórios violentos, como os motins, ataques à propriedade ou a pessoas, bloqueios de estradas, tendem a ser mais frequentes (apesar de níveis baixos). E embora em Portugal haja uma maior presença de repertórios de protesto disruptivo (ocupações e boicotes), estes tendem a ser pacíficos.

Em Espanha, as assembleias populares são ainda a mais importante forma de ação coletiva. Este repertório, baseado numa ocupação permanente do espaço público e organizado segundo práticas de democracia direta, opõe-se aos partidos políticos e à democracia representativa em geral. Pelo contrário, a cultura do protesto em Portugal não rejeita, mas antes se articula com, as instituições da democracia representativa.

Certas características estruturais dos dois países são bastante semelhantes, e por isso não podem explicar as variações encontradas a nível dos padrões de protesto entre os dois países (ex.: duração do próprio regime democrático; tipo de regime não democrático anterior). Os níveis de desenvolvimento ou de igualdade socioeconómica podiam constituir uma explicação possível. Mas sendo Espanha o país com melhor desempenho nestas dimensões, seria também de esperar que o seu padrão de protesto fosse mais pacífico, algo que não acontece. É em Portugal que encontramos um protesto mais pacifico e cívico.

Embora carecendo ainda de uma análise empírica mais aprofundada e completa, pensamos que as razões explicativas para as diferenças a nível da ação coletiva e do padrão de protesto entre Portugal e em Espanha radicam no tipo e nas consequências das diferentes formas como fizeram a sua transição para a democracia durante a década de 1970. Em ambas as democracias, a dimensão do protesto, tanto em número de eventos como de participantes, foi mais ou menos semelhante. Mas a relação que os movimentos sociais estabeleceram com o estado e as instituições foi muito mais variada. Em Portugal, a crise do estado que desencadeou um processo de transição social-revolucionário de inspiração socialista, permitiu uma muito maior margem de ação e impacto imediato dos movimentos sociais e do protesto do cidadão comum na formação das instituições, $\mathrm{o}$ que fez com que na longa duração houvesse uma maior abertura ao protesto, como atesta a facilidade com que os partidos tradicionais, os sindicatos ou o poder local apoiam os movimentos sociais. Isto explica também a natureza mais pacífica e a prevalência de temas socioeconómicos e dos sindicatos no protesto em Portugal face a Espanha. Neste último caso, pelo contrário, a parcial continuidade das instituições e do estado do regime anterior cristalizou as clivagens regionais do passado, fazendo com que os aliados do protesto sejam sobretudo partidos regionalistas ou partidos que durante bastante tempo foram exteriores ao próprio sistema partidário (ex: Podemos). Isto fez também perdurar em Espanha uma cultura e formas de organização do protesto (ex: assembleias, acampadas) distanciadas da política tradicional e seus atores. 
Do ponto de vista teórico, este artigo vê com algum ceticismo dois pressupostos fundamentais das teorias contemporâneas do protesto e da relação deste com a qualidade da democracia. O primeiro pressuposto argumenta que quanto maior for a dimensão do protesto, maior a capacidade de os grupos populares e o cidadão comum influenciarem o processo de decisão democrático. No entanto, a dimensão do protesto, medida quer em número de eventos, quer de participantes, não é assim tão diferente entre Portugal e Espanha. Ambos os países apresentam níveis similares.

O segundo pressuposto defende que os ciclos de protesto contribuem para a democracia quanto mais forem protagonizados por alianças plurais entre movimentos sociais e partidos políticos emergentes, e por movimentos sociais com lideranças profissionalizadas, uma rede burocrática desenvolvida e uma organização à escala nacional. Contudo, este estudo contesta também esta asserção. É no caso espanhol que estas características mais predominam, mas é também aí que o protesto adquire traços menos democráticos (ex: violência), onde há mais eventos que rejeitam a legitimidade do regime político, onde mais se verifica uma polarização entre blocos de radicalismo de esquerda e conservadorismo de direita e onde os movimentos estão desconectados da política institucional e partidária tradicionais.

O modelo de protesto localista, de pequena dimensão e informal que predomina em Portugal, e onde o poder local é um aliado decisivo, paradoxalmente parece ser criador de uma dinâmica política mais democrática. É neste país que a polarização é praticamente inexistente e onde uma cultura cívica de disrupção pacífica, que também atinge proporções muito elevadas em momentos de crise política à escala nacional, como a grande recessão entre 2010 e 2014, mais se manifesta. Na medida em que uma das supostas causas da crise das democracias contemporâneas é o declínio das organizações de massas tradicionais, como os partidos, os sindicatos e as grandes organizações cívicas, investigação comparada a partir do caso português poderá iluminar transformações em curso e formas emergentes de cultura cívica e de protesto que revejam essa interpretação e apontem para a existência de modelos alternativos na relação entre os cidadãos e a política.

\section{Referências bibliográficas}

Accornero, Guya, e Pedro Ramos Pinto (2015), "'Mild Mannered'? Protest and Mobilisation in Portugal under Austerity, 2010-2013”, West European Politics, 38 (3), pp. 491-515. Amenta, Edwin (2006), When Movements Matter. The Townsend Plan and the Rise of Social Security, Princeton e Oxford, Princeton University Press.

Amenta, Edwin, e Drew Halfmann (2012), “Opportunity Knocks. The Trouble with Political Opportunity and What You Can Do about It?", em Jeff Goodwin e James M. Jasper, Political Opportunities and Emergence of Protest, Stanford, Stanford University Press, pp. 227-239.

Banaszak, Lee Ann (1996), Why Movements Succeed or Fail. Opportunity, Culture, and the Struggle for Woman Suffrage, Princeton, Princeton University Press. 
Bernhard, Michael, Tiago Fernandes, e Rui Branco (2017), “Civil society and democracy in an era of inequality: introduction", Comparative Politics, 49 (3), pp. 209-309.

Carvalho, Tiago (2018), Contesting Austerity: A Comparative Approach to the Cycles of Protest in Portugal and Spain under the Great Recession (2008-2015), Cambridge, Universidade de Cambridge, tese de doutoramento.

Della Porta, Donatella, Massimiliano Andretta, Tiago Fernandes, Francis O'Connor, Eduardo Romanos, e Markos Vogiatzoglou (2017), Late Neoliberalism and its Discontents. Comparing Crises and Movements in the European Periphery, Londres, Palgrave Macmillan.

Della Porta, Donatella, Massimiliano Andretta, Tiago Fernandes, Eduardo Romanos, e Markos Vogiatzoglou (2018), Legacies and Memories in Movements. Justice and Democracy in Southern Europe, Oxford, Oxford University Press.

Disobedient Democracy Project (website), disponível em: https://disdem.org/ (última consulta em maio de 2021).

Dolenec, Danijela (2017) “Disobedient democracy: a comparative analysis of contentious politics in the European semi-periphery", Zagreb, University of Zagreb, manuscrito.

Dolenec, Danijela, AnaBalkovic, Karlo Kralj, Daniela Širinic, Eduardo Romanos, e Tiago Fernandes (2019), "Disobedient democracies in the European semi-periphery", Zagreb, University of Zagreb, manuscrito.

Ekiert, Grzegorz, e Jan Kubik (1999), Rebellious Civil Society. Popular Protest and Democratic Consolidation in Poland, 1989-1993, Ann Arbor, University of Michigan Press.

Fernandes, Tiago (2014), A Sociedade Civil, Lisboa, Fundação Francisco Manuel dos Santos.

Fernandes, Tiago (2017), "Late neoliberalism and its discontents: the case of Portugal”, em Donatella della Porta, Massimiliano Andretta, Tiago Fernandes, Francis O'Connor, Eduardo Romanos e Markos Vogiatzoglou, Late Neoliberalism and Its Discontents. Comparing Crises and Movements in the European Periphery, Londres, Palgrave Macmillan, pp. 169-200.

Fernandes, Tiago (2018) “Organizational sources of social resilience and progressive governance: Portugal during and after austerity (2008-2015)", em Francisco Bethencourt (org.), Inequality in the Portuguese-Speaking World, Brighton, Sussex Academic Press.

Fernandes, Tiago, e Rui Branco (2017), “Long-term effects: social revolution and civil society in Portugal, 1974-2010", Comparative Politics, 49 (3), pp. 411-430.

Fishman, Robert (2004), Democracy's Voices. Social Ties and the Quality of Public Life in Spain, Ithaca e Londres, Cornell University Press.

Fishman, Robert (2011), “Democratic practice after the Revolution: the case of Portugal and beyond", Politics and Society, 39 (2), pp. 233-267.

Fishman, Robert (2018), Democratic Practice. Origins of the Iberian Divide in Political Inclusion, Oxford, Oxford University Press.

Freire, André, Marco Lisi, e José Manuel Leite Viegas(orgs.) (2015), Crise Económica, Políticas de Austeridade e Representação Política, Lisboa, edição da Assembleia da República. 
Goodwin, Jeff (2012), “Conclusion: are protesters opportunists? Fifty tests”, em Jeff Goodwin e James Jasper (orgs.), Contention in Context. Political Opportunities and the Emergence of Protest, Stanford, Stanford University Press, pp. 278-300.

Goodwin, Jeff, e James M. Jasper, Political Opportunities and Emergence of Protest, Stanford, Stanford University Press.

Goss, Kristin A. (2006), Disarmed. The Missing Movement for Gun Control in America, Princeton e Oxford, Princeton University Press.

Hall, Peter, e Michele Lamont (orgs.) (2013), Social Resilience in the Neoliberal Era, Cambridge, Cambridge University Press.

Hutter, Stephen (2014), "Protest event analysis and its offspring", em Donatella della Porta (org.), Methodological Practices in Social Movement Research, Oxford, Oxford University Press, pp. 335-367.

Kriesi, Hanspeter, Ruud Koopmans, Jan Willem Duyvendak, e Marco G. Giugni (1995), New Social Movements in Western Europe. A Comparative Analysis, Minneapolis, Univesity of Minnesota Press.

Magalhães, Pedro T. (2018), “Legado partilhado, ruturas divergentes: a democracia subnacional", em Tiago Fernandes (org.), Variedades de Democracia na Europa do Sul. Uma Comparação entre França, Itália, Grécia e Portugal, 1968-2010, Lisboa, Imprensa de Ciências Sociais, pp. 225-254.

Portos, Martín (2016), “Taking to the streets in the context of austerity: a chronology of the cycle of protests in Spain, 2007-2015", Partecipazione e Conflitto, 9, pp. 181-210.

Romanos, Eduardo (2017) “Late neoliberalism and its indignados: contention in austerity Spain", em Donatella della Porta, Massimiliano Andretta, Tiago Fernandes, Francis O'Connor, Eduardo Romanos, e Markos Vogiatzoglou, Late Neoliberalism and Its Discontents. Comparing Crises and Movements in the European Periphery, Londres, Palgrave-Macmillan, 131-167.

Romanos, Eduardo, e Igor Sádaba (no prelo) “Evolución de la protesta en España (2000-2017): un análisis de sus ciclos y características", Revista Española de Investigaciones Sociológicas.

Tarrow, Sidney (1990), Democrazia e Disordine. Movimenti di Protesta e Politica in Italia, 1965-1975, Roma, Laterza.

Tarrow, Sidney (1995), “Cycles of collective action: between moments of madness and the repertoire of contention", em Mark Traugott (org.), Repertoires and Cycles of Collective Action, Durham e Londres, Duke University Press, pp. 89-116.

Tarrow, Sidney (1997), El Poder en Movimiento. Los Movimientos Sociales, la Acción Colectiva y la Política, Madrid, Alianza Editorial.

Tilly, Charles (1986), The Contentious French, Cambridge e Londres, The Belknap Press of Harvard University Press.

Tiago Fernandes. Professor associado com agregação, Departamento de Ciência Política e Políticas Públicas, Iscte - Instituto Universitário de Lisboa, Avenida das Forças Armadas, 1649-026 Lisboa.

E-mail: Tiago.Luis.Fernandes@iscte-iul.pt

ORCID: https://orcid.org/0000-0002-3020-7753 
Cláudia Araújo. Investigadora de doutoramento, Faculdade de Filosofia, Universidade de Barcelona, Gran Via de les Corts Catalanes, 58508007 Barcelona. E-mail: clrodrig52@alumnes.ub.edu

ORCID: https://orcid.org/0000-0002-6607-5123

Isabel Gorjão Santos. Investigadora de doutoramento, Departamento de Ciência Política, FCSH - UNL, Avenida de Berna, 26-C / 1069-061 Lisboa.

E-mail: isabel.gorjao.santos@gmail.com

ORCID: https://orcid.org/0000-0001-5909-2008

Eduardo Romanos. Professor, Departamento de Sociología Aplicada, Facultad de Ciencias Políticas y Sociología, UCM - Campus de Somosaguas, 28223 - Pozuelo de Alarcón, Madrid, España.

E-mail: eromanos@ucm.es

ORCID: https://orcid.org/0000-0002-0200-3470

Receção: 11 de outubro de 2020 Aprovação: 18 de fevereiro de 2021 